\author{
Cadernos de \\ ESTUDOS LINGǘlsTICOS - (54.2), Campinas, Jul./Dez. 2012
}

\title{
NO (PER)CURSO DE FERDINAND DE SAUSSURE A HETERO- DIMENSÃO É FUNDANTE
}

\author{
MARIA HOZANETE ALVES DE LIMA*
}

\begin{abstract}
RESUMO
Este trabalho investiga as marcas de uma hetero-dimensão presente e fundante da epistemologia saussureana. Para tanto, analisaremos de que forma, no Curso de Linguística Geral e nos manuscritos de Ferdinand de Saussure, essa hetero-dimensão é constitutiva do próprio funcionamento linguístico e os efeitos que ela promove no curso teórico do linguista genebrino. Nosso trabalho segue de perto as leituras sobre a obra de Saussure trilhada por Milner (1987; 1989), Bouquet (1999), Normand (2000) e, até mesmo, o próprio psicanalista Jacques Lacan (1998). Nossos estudos se concentram em dois pontos fulcrais que dizem da estrutura e do funcionamento da língua: as características do signo linguístico e as relações sintagmáticas e paradigmáticas. Será, portanto, no seio da teorização sobre o signo e dos dois eixos que comandam o funcionamento linguístico que demarcaremos como a hetero-dimensão tem sido considerada e os efeitos discursivos que tem produzido.
\end{abstract}

Palavras chave: hetero-dimensão; epistemologia saussureana; relações sintagmáticas e paradigmáticas.

\section{RESUMÉ}

Ce travail enquête les marques d'une hétéro-dimension présente dans l'épistémologie saussurienne. Nous analysions comment, dans le Cours de Linguistique Générale et dans les manuscrits de Ferdinand de Saussure, cette dimension est constitutive du fonctionnement linguistique lui-même et des effets qu'elle promeut dans le parcours théorique du linguiste genevois. Notre travail suit les lectures sur l'oeuvre de Saussure développés par Milner (1987; 1989), Bouquet (1999), Normand (2000) et, même si, le psychanaliste Jacques Lacan (1998). Nos études se concentrent sur deux points centraux qui disent de la structure et du fonctionnement de la langue: les caractéristiques du signe linguistique et les relations syntagmatiques et paradigmatiques. Ce sera, donc, dans le cœur de la théorisation sur le signe et des deux essieux qui commandent le fonctionnement linguistique que nous délimiterons comme la hétéro-dimension a été considérée et les effets discursifs qu'elle a produit. Mots-Clés: hétéro-dimension; l'épistémologie saussurienne; relations syntagmatiques et paradigmatiques.

"UFRN, Natal (RN), Brasil. hozalima@ufrnet.br

** O termo hetero-dimensão é aqui reservado para falar da duplicidade de sentidos, da não-univocidade, de um idêntico que retorna sobre a forma do não-idêntico, e que é inerente à língua. À medida que o texto vai sendo desenvolvido, o leitor acompanhará a construção do próprio termo, explicitado de modo aprofundado na terceira parte do trabalho. 


\title{
1. PALAVRAS INICIAIS: NO PRINCÍPIO, A LÍNGUA
}

O pressuposto que subjaz a qualquer investigação que se construa sob a égide da Linguística poderia, grosso modo, ser dito assim: no princípio está a língua; $e$ a língua tem um funcionamento. Em contrapartida, ao mesmo tempo em que essa proposição se pretende posta, "compreender" esse funcionamento revela um empreendimento e uma tomada de posição. Consoante Jean-Claude Milner (1989), é sempre do lugar de que pode construir um "saber sobre a língua" que se dão os primeiros passos. A diversidade de encontros e desencontros teóricos diz da dificuldade que há em se fechar qualquer discussão sobre o funcionamento da língua, mas, aos olhos de Milner, embora a Linguística, e tudo que se construa sob seu espaço discursivo, esteja fadada a nunca acabar o dispositivo de suas argumentações, cada dispositivo se revela como "um modo de ser inédito de concluir" (MILNER, 1989. p.336).

O próprio Ferdinand de Saussure, sob cujo nome se assenta o nome da $\mathrm{Ci}$ ência Linguística e o recorte da língua como objeto dessa ciência, convidara a ver, já no Curso de Linguística Geral (doravante CLG), que é uma questão particularmente difícil apreender "o objeto ao mesmo tempo integral e concreto da Linguística” (SAUSSURE, 1999, p. 15). O discurso sobre a língua estaria sempre implicado com um ponto de partida, que pode ser lido como aquilo que se repete e permite notação (MILNER, 2002), mas em toda sua busca, esse objeto "integral" se mostrava uma realidade escorregadia, ofuscante, de modo que cada ponto de partida eleito parecia ser não mais que uma realidade aparente (SAUSSURE, apud BOUQUET, 1999, p. 69). Nessa linha de compreensão, Saussure defendera que seu ensinamento deveria ser tomado especialmente como uma "filosofia da linguística”. Seu desabafo revela bem em que situação ele se encontrava:

\begin{abstract}
Vejo-me diante de um dilema: ou expor o assunto em toda sua complexidade e confessar todas as minhas dúvidas, o que não pode convir para um curso que deve ser matéria de exame, ou fazer alguma coisa de simplificado, melhor adaptado a um auditório de estudantes que não são linguistas. Mas, a cada passo, vejo-me retido por escrúpulos. Para se realizar, é necessário, a mim, menos meditação exclusiva (SAUSSURE, apud GODEL,
\end{abstract} 1969).

Acostumados ao CLG, e às leituras que fazemos continuamente dele, ouvimos falar pouco ou quase nada da perspectiva saussuriana que toma a língua como uma "realidade misteriosa". Encontramo-la, de modo mais forte, nos manuscritos saussurianos, nas anotações dos alunos que frequentaram os cursos oferecidos pelo linguista em Genebra e nos estudos sobre esse material desenvolvidos por Simon Bouquet (1999), Robert Godel (1969.) e Jean Starobinski (1974), embora eles reconheçam que o CLG já é, ele próprio, o espaço que simboliza bem as dificuldades enfrentadas por Saussure.

Tais dificuldades simbolizam que a língua estaria desde sempre implicada com a ordem daquilo que se repete e permite notação, formalização, categorização, e com a ordem de um repetível que não apenas escapa a qualquer categorização, mas faz dela uma "realidade aparente". Não obstante seja desse modo, esse 
repetível também é fundante, já que desenha a hetero-dimensão ${ }^{1}$ constitutiva do funcionamento linguístico ${ }^{2}$. Milner metaforiza de um modo especial essa dualidade; para ele, isso se justifica pelo fato de que "toda língua é capaz de poesia" e, se toda língua é capaz de poesia, é porque "toda língua é capaz de gramática", (MILNER, 1989, p.53) ${ }^{3}$.

A partir desse contorno, Milner (1987) sublinha que a língua é constitutiva de um todo suportando (ou suportado sobre) o não-todo, de modo que há um ponto na língua que impede que (a partir dela) se diga tudo sobre ela (ou que ela diga tudo, ou que tudo seja dito por ela).

Tomando por base essas considerações, buscarei mobilizar uma discussão que tem como ponto central o reconhecimento de que há em Saussure a escuta de uma hetero-dimensão que não apenas foi reconhecida por ele, mas se encontra subjacente em seu construto. Nossa leitura não é, por assim dizer, original, já que várias vozes e leituras são responsáveis e convocadas para a tessitura do texto.

Para tanto, elegemos um ponto específico em que a hetero-dimensão tem causado certo efeito, seja no CLG ou nos manuscritos saussurianos, qual seja, as relações paradigmáticas ${ }^{4}$.

\title{
2. O NEGATIVO, O RELATIVO, O OPOSITIVO
}

Saussure define a língua como um sistema de relações entre valores negativos, relativos e opositivos. A definição de "valor" nos parece perturbadora, posto que a "positividade" que caracterizaria melhor uma ciência é dita aqui pela negação de qualquer "positivo".

O positivo na linguagem é o negativo. Isso faz efeito em Saussure no momento em que deve escolher os termos com os quais vai lidar em seu construto. Cada termo eleito, se ora pareceria dotado de clareza, de outro, tornava-se obscuro, dada a possibilidade de sentidos que um mesmo termo poderia evocar. Assim, Saussure reconhece que "um dia haverá um livro especial e muito interessante a ser escrito sobre o papel da palavra como principal perturbador da ciência das palavras" (SAUSSURE, apud BOUQUET, 1999, p. 71):

\begin{abstract}
Para mim, quando se trata de linguística, isto é acrescido pelo fato de que toda teoria clara, quanto mais clara for, mais inexprimível em linguística ela se torna, porque acredito que não exista um só termo nesta ciência que seja fundado sobre uma idéia clara e que, assim, entre o começo e o fim de uma frase, somos cinco ou seis vezes tentados a refazê-la. (SAUSSURE, apud STAROBINSKI, 1974, p.11).
\end{abstract}

Se esses dilemas parecem não ter voz ou não ser autorizados pelo CLG, para Simon Bouquet, isto se deve à tomada de posição dos redatores, que pretendiam

\footnotetext{
${ }^{1} \mathrm{O}$ termo fundante é utilizado aqui a partir de Teresa Guimarães de Lemos (de LEMOS, 1994).

${ }^{3}$ Minhas leituras tiveram como ponto de partida os estudos desenvolvidos pela linguista Claudia Lemos que traz para seu campo de investigação as releituras lacanianas da linguística saussuriana.

${ }^{4} \mathrm{O}$ termo hetero-dimensão é utilizado, nesse trabalho, a partir de Jacques Lacan (1999).
} 
ALVES DE LIMA - No (per)curso de Ferdinand de Saussure...

apresentar ao leitor, sob um "discurso homogêneo", o claro programa de uma ciência, de sorte que podaram tudo que sugerisse a sombra, organizando a obra consoante "a lógica de um sistema acabado" - longe do que deixava ver as anotações e os manuscritos. Por outro lado, se as notas e os manuscritos "testemunham um pensamento formado por pinceladas, que chega a seus desenvolvimentos a assumir a forma de aforismos", não significa que falte nas reflexões do genebrino um sistema elaborado, pois o conjunto de seu pensamento aponta para o "discurso de uma pura epistemologia programática da ciência da linguagem" (BOUQUET, op. cit, p. 14).

Apesar dos esforços dos editores, o CLG não conseguiu sustentar, em linhas gerais, a claridade desejada: recaem sobre ele vestígios de outras pesquisas, quais sejam, as reflexões sobre a filosofia hindu e os trabalhos de mitologia e poética, concebidos, de modo metafórico, como a "face noturna" dos trabalhos do linguista, em contraposição a uma possível "face diurna" (BOUQUET, op. cit., p.72). Essas "faces" são, ainda, afirmadas através da expressão "linguista durante a semana, leitor de poetas no sábado” (MILNER, 1987, p.75). Françoise Gadet e Michel Pêcheux reconhecem nisto os dilemas enfrentados por Saussure em sua dupla tarefa: apresentar de maneira clara um assunto coberto de complexidades e compreender o movimento interno ao funcionamento dos anagramas:

ao nome de Saussure, os linguistas se dividem, porque o próprio Saussure porta essa divisão, que se imagina na fácil dicotomia opondo o Saussure do Curso de Linguística Geral (tanto mais claro e frio como ele foi comentado após a leitura dos editores) àquele dos Anagramas (em que circula a obscura loucura da decriptagem, das associações escondidas nos versos saturninos) (GADET \& PÊCHEUX, 1981, p. 52).

Não obstante a língua seja um sistema de valores negativos, opositivos e relativos, Saussure reconhece ser necessário pensar em uma positividade, ainda que imaginária. Para Milner, é a isto a que se presta a teoria do signo, marcar uma positividade, uma estabilidade, através de um efeito de ancoragem que marca a relação de dependência entre o significante e o significado ${ }^{4}$. Por conseguinte, mesmo que a língua gire em torno da diferença e do negativo, "somos forçados a tomar como ponto de partida aquilo que nos parece ser positivo", já que a "unidade" é, em realidade, "sempre imaginária" (SAUSSURE, 2002, p. 83):

\footnotetext{
Como não há nenhuma unidade (de qualquer ordem e de qualquer natureza que se imagine) que repousa sobre outra coisa que não diferenças, em realidade a unidade é sempre imaginária, somente há a diferença. Nós somos forçados a proceder com a ajuda de unidades positivas, sob a pena de ser o debate incapaz de materializar a massa dos fatos. Mas é essencial se recordar que estas unidades são um expediente inevitável de nossa [ ], e nada demais: o quanto antes se coloque uma unidade isto vem dizer que é necessário [ ] para prestar momentaneamente uma existência separada à [ ] (SAUSSURE, 2002, p.83 - tradução minha).
}

${ }^{4}$ Jacques Lacan (1998) chama esta ancoragem de "ponto de basta", ponto em que o significante e o significado param seu deslizamento incessante e se prendem um ao outro. 


\section{O CLG - UM NÃO-TODO POR ONDE A PRÓPRIA LÍNGUA ESCAPA}

No capítulo II do CLG, de acordo com a editoração de Charles Bally e Albert Sechehaye, Saussure recorre à delimitação como recurso para reconhecer a identidade das unidades linguísticas. Para ele, a entidade linguística "só existe pela associação do significante e do significado" estando delimitada na cadeia fônica quando separada de tudo que a rodeia. Em outras palavras, a unidade linguística é "uma porção de sonoridade que, com exclusão do que precede e do que segue na cadeia falada, é significante de certo conceito" (SAUSSURE, 1999, p.119-20). Embora existam, não podemos segurar que elas existam do modo como consideramos, visto que "a língua apresenta pois este caráter estranho e surpreendente de não oferecer entidades perceptíveis à primeira vista, sem que se possa duvidar, entretanto, de que existam e que é seu jogo que a constitui" (idem, p.124).

Saussure toma como exemplo a estrutura "si je la prends" que pode ser delimitada, de acordo com o sentido, como "si- ž-la-prã" (si je la prends) ou "si-žl-aprã (si je l'apprends), e, para ele, aquele "que conhece a língua delimita-lhe as unidades por um método bastante simples": basta colocar "a pessoa no plano da fala" (SAUSSURE, 1999, p.121) e "representá-la pela cadeia dos conceitos e das imagens acústicas. Aos olhos de Claudia Lemos (1998), nesse momento, Saussure traz para o interior de sua discussão a fala que inicialmente havia separado da língua, e, "ainda que separe a língua da fala, fazendo da primeira o objeto da Linguística, não consegue se deter na primeira e deixar de procurar o lugar da fala e do falante no funcionamento da língua" Nessa busca, Saussure se depara com o fato de que "é impossível para o falante, da posição que lhe é dada pelo ato de falar, escolher, decidir e controlar o que da língua escorre para sua fala" (LEMOS, 1998, p. 6).

O exemplo tomado por Saussure acaba por estenografar outra coisa, que a língua é sobrecarregada de homofonia, de efeitos que promovem dubiedade, suspeição, escutas inesperadas e, por que não dizer, tomadas de posição.

A homofonia aparece não como lugar através do qual se possa identificar as unidades da língua, uma vez que ela vem "desestratificando, confundindo sistematicamente som e sentido, menção e uso, escrita e representado, impedindo, com isto, que um estado possa servir de apoio para destrinchar um outro" (MILNER, 1987, p.15). O "sentido", aquilo que seria chamado para autorizar a delimitação, ou, fazendo uso das palavras de Claudia Lemos (1998, p.9), "a operação pela qual se impõe uma delimitação à cadeia remete a algo mais do que o simbólico que a língua presentifica". Deste modo, o que a língua presentifica pode remeter a algo mais que um sujeito capaz de delimitar unidades e sustentar o sentido destas. O jogo da homofonia sinaliza que na língua há um espaço que pode ser caracterizado por uma "hetero-dimensão", é o espaço do equívoco, da duplicidade de sentidos, da não-univocidade, de um idêntico que retorna sobre a forma do não-idêntico, e que é inerente à linguagem (GADET \& PÊCHEUX,1981).

Levando em conta a não-univocidade, Milner aponta para a questão de que a teorização da língua está presa na forquilha da completude e da não-completude 
que responde por uma "falta" irremediável. Falta que, nas palavras de Teresa Lemos (1994), não diz da falta de um elemento, e sim, que há uma dimensão na língua que é fundante, a saber, a dimensão do equívoco. É a dimensão do não-idêntico e do não-idêntico a si que se encontra sob a rubrica do equívoco: "tudo aquilo que promove homofonia, homossemia, homografia, tudo o que suporta o duplo sentido e o dizer em meias palavras, incessante tecido de nossas conversações" (MILNER, 1987, p.12-13). O objeto integral da Linguística é constantemente desestratificado por esse não-todo lido como o real da lalangue. Traduzido como alíngua, esse termo foi forjado por Jacques Lacan e significativamente usado por Milner (1987, p. 19) que assim o define: "Alíngua sendo em toda língua o registro que a consagra ao equívoco", de sorte que "a língua suporta o real da alíngua".

A alíngua confere uma a uma as séries homogêneas constituídas para compreender o funcionamento da língua: a exemplo dos fonemas, dos morfemas, da sintaxe, do sentido dicionarizado, etc. e diz que a língua é um espelho que deforma, é a mesma, mas não oferece a mesma fisionomia de onde quer que se olhe.

A própria teoria do valor, para muitos, abre essa dimensão, pois ela acaba por revelar que o sistema é capaz de subversão, já que nele, algo pode ser representado por não importa o que venha lhe representar. A consequência disto é anotar que na língua se impõe algo da ordem do absurdo, do negativo, da metáfora, "sendo exatamente aí que a ciência da linguagem é concernida pelo registro do inconsciente" (GADET \& PÊCHEUX, 1981, p. 57-8).

A hetero-dimensão vai, assim, se esparramando em diferentes lugares. Nas notas de rodapé, nas discussões que os editores fazem, no coração da teoria do valor, do eixo associativo, quando apontam para um tipo de relação "anormal"; aquelas que se dão por "simples comunidade de imagens auditivas" e "perturbam a inteligência do discurso". Trata-se, especificamente, das "confusões absurdas" desenhadas por "uma categoria inferior de jogos de palavras", por assim dizer, desenhadas pela homonímia (SAUSSURE, 1999, p. 145-146):

Na língua não há senão diferença sem termos positivos, defende Saussure. Dizendo isto, diz mais, "a língua é um sistema em que os termos são solidários e o valor de um resulta tão somente da presença simultânea de outros" (SAUSSURE, op.cit., p.139). Os termos são indissociáveis e se encontram numa relação dupla: são as relações paradigmáticas e sintagmáticas que, seguindo uma metáfora lacaniana "são como anéis cujo colar se fecha no anel de um outro colar feito de anéis” (LACAN, 1998, p.505). Tal funcionamento é exemplificado por Saussure através do diagrama:

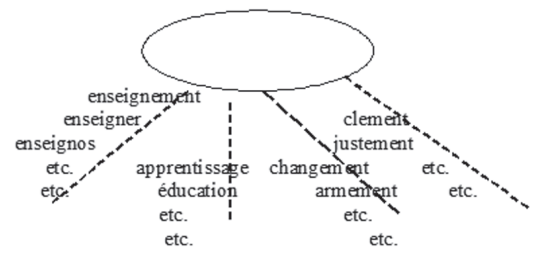

(SAUSSURE, 1999, p.146) 
No interior da palavra, a relação sintagmática, in praesentia, em que todos os elementos se interligam e se significam mutuamente; subjacente a ela, a paradigmática, uma família associativa, in absentia, que mantém relações de toda ordem. Destacam-se nela quatro linhas de associações a partir do termo dado: o primeiro tecido, enseigner, enseignons, etc, tem como ponto de partida tanto a semelhança formal quanto semântica; o segundo, apprentissage, éducation, etc., revela a semelhança semântica entre os termos; o terceiro, changement, armement, etc., destaca termos que apresentam o mesmo tipo de sufixo - ment - que formaria substantivos abstratos; e, por fim, uma trama entre termos que apresentam semelhança acústica somente na terminação. Temos aqui "tanto comunidade dupla do sentido e da forma como comunidade de forma ou de sentido somente" (SAUSSURE, 1999, p.146).

Uma vez que a cadeia paradigmática e a cadeia sintagmática se sustentam de maneira recíproca, relações de várias ordens podem imperar, embora uma preciosa nota de rodapé do Curso apresente algumas reservas em relação a certos tipos de associações ${ }^{5}$ :

Este último caso é raro e pode passar por anormal, pois o espírito descarta naturalmente
as associações capazes de perturbarem a inteligência do discurso; sua existência, porém,
é provada por uma categoria inferior de jogos de palavras que se funda em confusões
absurdas que podem resultar do homônimo puro e simples, como quando se diz em
francês: Les musiciens produisent les sons e les grainitiers les vendent" [ou, em português,
"Os músicos produzem as notas e os perdulários as gastam"]. Cumpre distinguir este caso
daquele em que uma associação, embora fortuita, se pode apoiar numa aproximação de
idéias (cf. francês ergot: ergoter, alemão blau: durchbläuen, "moer de pancadas"); trata-
se, no caso, de uma interpretação nova de um dos termos do par; são casos de etimologia
(...); o fato é interessante para a evolução semântica, mas do ponto de vista sincrônico
cai simplesmente na categoria ensinar: ensino mencionada acima (SAUSSURE, 1999,
p.145-146, itálico nosso).

Esta nota de rodapé, assinada pelos editores, afirma que aquele tipo de associação seria naturalmente "descartado pelo espírito", porém, como assenta Milner (1983, p.40), "nenhum ser falante pode se vangloriar de ter o controle dos ecos múltiplos de seu dizer". Milner nos faz considerar o que afirma o psicanalista Jacques Lacan, no livro As Formações do Inconsciente. Jacques Lacan pontua que o significante, relido de Saussure, não existe para servir às efusões da consciência", pontuando a hetero-dimensão do significante (LACAN, 1999, p.110).

Dada uma palavra, não se pode prever o número de palavras que a memória pode sugerir ou a ordem em que podem aparecer, pois "um termo dado é como o

${ }^{5}$ Essa nota de rodapé é tomada como sendo, exclusivamente, dos editores do CLG. Todavia, é necessário considerar que os editores do CLG escrevem a partir de anotações de alunos que freqüentaram os cursos oferecidos por Saussure. Assim, tudo o que está no CLG pode ser considerado fruto da atuação do lingüista nos cursos oferecidos por ele. Essa nota de rodapé, como muitas outras do CLG por sua vez, paradoxalmente, conjugam as vozes do lingüista com a dos editores. É difícil, mesmo que tenhamos acesso aos famosos manuscritos de Ferdinand Saussure, defender que as notas dos editores não nasçam de reflexões saussurianas escutadas por seus alunos. 
ALVES DE LIMA - No (per)curso de Ferdinand de Saussure...

centro de uma constelação, o ponto para onde convergem outros termos coordenados, cuja soma é indefinida" (SAUSSURE, 1999, p. 146). Disto segue que em toda cadeia há um resto, ou, dizendo de outro modo, há sempre outro (não é isto que nos diz a etimologia da palavra etc, et cetera - e outros). Seguindo essa linha de pensamento, Claudine Normand (1990) fala do resto invariável e indefinido intervindo em variadas formas e graus na significação, de modo que "enseignement" pode evocar, por exemplo, en s'aimant. Assim sendo, as relações associativas deixam ver que o mecanismo linguístico apenas se deixa apreender parcialmente, pois "tudo que depende de um sujeito na singularidade das associações escapa à análise" (NORMAND, 2000, p.155, tradução nossa) ${ }^{6}$.

Há muita discussão sobre essas relações. Túlio de Mauro, comentando sobre elas, defende que a "a teoria freudiana dos lapsus linguae pode ser considerada como uma confirmação clínica da hipótese de Saussure” (MAURO, 1982, p.469). Arrivé (1999) ressente-se do fato de que as considerações dos editores tenham sido relegadas a uma simples nota. Para ele, os editores deveriam ter tido uma indulgência em relação a esse tipo de associação. Provavelmente, uma indulgência freudiana.

\section{OS ANAGRAMAS: O ESPÍRITO QUE PERTURBA A INTELIGÊNCIA DO DISCURSO}

Os Anagramas seriam, de certo modo, o espaço privilegiado para o exercício dessa indulgência. Jean Starobinski (1974) anota que Saussure dedicara mais de três anos aos estudos sobre os anagramas e eles podem ser encontrados em 140 cadernos e alguns escritos. Estudando o "verso saturnino", Saussure desenvolveu a teoria de que os poetas latinos deliberadamente ocultavam nomes de deuses ou pessoas a quem os poemas eram dedicados, ou até mesmo nomes das próprias pessoas que encomendavam os poemas. Estes nomes apareciam distribuídos entre segmentos fônicos de natureza variada: vogais, consoantes e sílabas.

Estudando a poesia clássica, o linguista se depara com os anagramas, que consistem na composição de um texto sob outro texto, de sorte que em um poema dedicado a Hércules, o nome do herói seguiria uma distribuição especial ao longo do texto, formando uma espécie de manequim: H_E_R_C_O_L_E_I. Os espaços em branco seriam os lugares de atualização do poema. A distribuição do "manequim" poderia obedecer a outras divisões, dentre elas, poderíamos ter HE, RC, OL CL, EI. A partir do manequim, o poeta se "impregnaria" do maior número possível de segmentos fônicos para sua composição. Saussure aposta na capacidade dos antigos poetas em "obsessivamente" (termo usado por Starobinski) se entregarem à análise fônica das palavras, seja para construir séries acústicas, seja para se

${ }^{6}$ Consoante Claudia Lemos, as potencialidades das relações entre os elementos linguísticos são infinitas. Todavia, "no Curso, todos os comentários sobre relações que produzem formas não-esperadas (não calculadas) visam a limitar a idéia de que o mecanismo funcione além da gramática” (LEMOS, 1998). 
referir a certo nome. A palavra afleita, por exemplo, poderia ser usada para lembrar Hercolei. Embora não esperasse encontrar a "repetição" em todos os versos, poderia encontrá-la na maior parte deles. Em Subigit omne Loucanam opsidesque abdouicit, por exemplo, teríamos: duas vezes ouc (Loucanam, abdoucit), duas vezes $d$ (opsidesque, abdoucit), duas vezes $b$ (subigit, abdoucit), duas vezes it (subigit, abdoucit), duas vezes $\breve{1}$ (subĭgit, opsĭdes), duas vezes ă (Loucanăm, ăbdoucit), duas vezes ŏ (ŏmne, ŏpsides), duas vezes $n$ (omne, Loucanam) e duas vezes $m$ (omne, Loucanam) (SAUSSURE, apud STAROBINSKI, 1974, p. 26). A técnica, como requerida por Saussure, falava do agrupamento entre coisas em comum - em comum com cada parte do nome distribuída - e combinação.

A procura das regras que orientavam a distribuição do material linguístico levara o estudioso ao princípio do "acoplamento": toda vogal e toda consoante em uso pela primeira vez seriam redobradas; obedeceriam ao "princípio de par", caracterizado pelo que chama de "dífono". Embora a aliteração, a rima e o ritmo estivessem implicados na composição anagramática, não eram tomados como primeiros. O veio condutor era uma palavra-tema, um nome, um "significantemestre" dado de antemão, que se distribuía no interior do texto formando uma espécie de "manequim". O lugar em cada verso onde se encontravam os fonemas do nome é tomado por Saussure como locus princeps.

Observando bem a análise, é possível perceber que, se os significantes "Hercolei" e "afleita" estão ligados pelos significantes "ei", outras relações encontram-se, na virtualidade, subjacentes, e que essas relações seriam completamente singulares, já que indefinidas.

Mas o objetivo de Saussure é encontrar, nessa realização específica, as relações dadas de antemão, de modo que tem uma dupla compreensão sobre a gênese do movimento. De um lado, confere a esse um traço de ordem religiosa, afirmando que, em tempos mais remotos, acreditava-se que as orações e as fórmulas deprecatórias dirigidas a alguma divindade só surtiriam efeito se estivessem implicadas com o nome divino (SAUSSURE, apud STAROBINSKI, op. cit., p.17). Por outro, anuncia ser uma "técnica poética", reflexo de um saber específico do poeta que, propositadamente, fazia surgir o mesmo sob a figura de outro.

A composição, todavia, mostrava-se enigmática, essencialmente porque não se reconhecia na literatura, nos tratados sobre versificação e técnica poética, qualquer traço referente a essa ordem seminal. Não ajudava o fato de que Saussure se deparava com anagramas em qualquer obra que ele abrisse ao acaso. Todo e qualquer texto, por fim, poderia padecer sob a pressão de um movimento que obedecia às leis de uma combinatória puramente, logo, o que Saussure estabeleceu não é compreendido como propriedade especial do verso saturnino, ou da poesia, mas uma propriedade da própria língua, "um escorregão inerente a toda linguagem" (GADET \& PÊCHEUX, 1981, p. 57).

Nas palavras de Starobinski, não só a poesia clássica, como previa Saussure, mas toda a linguagem seria, na verdade, combinação, mesmo que não intervenha a intenção explícita de praticar uma arte combinatória. O trabalho de Saussure abre a porta para que "decifradores", "cabalistas" ou "foneticistas" tenham um vasto campo, já que uma leitura atenta, simbólica ou numérica, pode fazer nascer 
ALVES DE LIMA - No (per)curso de Ferdinand de Saussure...

algo latente, um segredo escondido, "uma linguagem sob linguagem" (STAROBINSKI, op. cit., p.113). A causa enunciando-se não como o "indivíduo criador", mas a "palavra indutora".

Milner (1987) entende que Saussure "falha" ao supor que os anagramas eram construídos a partir de uma técnica. A prova esperada por Saussure seria encontrar textos sem anagramas, todavia, acaso ou não, qualquer texto pulsava diante dos olhos do genebrino. Se obra do "acaso", este parecia obedecer a certas leis. Jacques Lacan defende que Saussure não se dera conta do fato de que o próprio poeta era "devorado pelos versos, que entre eles falam sua ordem sem se preocupar com o que esse (poeta) sabe ou não", afirma Jacques Lacan (1970)7.

Saussure recorre a um escritor, considerando que esse pudesse lhe afirmar que ali residia uma técnica, um segredo, um saber, mas ninguém assume o "saber" dos anagramas. Porquanto, esse "saber" permanece na dimensão de "suposto", "saber, explícito e consciente, cuja ausência de todo traço deve ser atribuída a um segredo" (MILNER, op. cit., p.55). Jacques Lacan (1999) sublinha que, nos Anagramas, a suposição de que há um sujeito-poeta rebate na falta de evidências, pois o saber é do inconsciente, do Outro, sendo o Outro "um lugar em que se esforça para transferir o lugar do sujeito". Não sendo um sujeito, este Outro "é o depósito dos representantes representativos desta suposição de saber, e é isto que chamamos de inconsciente enquanto que o sujeito perdeu-se a si mesmo nesta suposição de saber". É o jogo combinatório dos significantes da língua, que se faz repetível. A escuta, ao que nos parece, se trataria, assim, de uma subjetividade, cujo locus princeps parecia ser o próprio Ferdinand de Saussure. Por este caminho, podemos pensar que a subjetividade seria o movimento de cada sujeito em estar em determinada posição de escuta, seja ela de sentidos estabilizados, de um efeito de positividade, de possibilidades de relações, ou de deslizamentos de sentidos.

De acordo com Lacan, a noção de subjetividade na língua "se afirma por uma via que passa por um lugar inteiramente diferente daquele em que se poderia erguer-lhes obstáculos" (LACAN, 1999, p.10). Tanto para o analista quanto para aqueles que procedem pela via do diálogo, a "subjetividade é o que ele tem de considerar em seus cálculos quando lida com aquele outro que pode introduzir nos cálculos dele seu próprio erro, e não procura provocar-se enquanto tal" (LACAN, 1999, p.190). A subjetividade na Psicanálise fala de um sujeito que falha na sua intenção de significar, nisto que é a intenção de significação, "dimensão da consciência, pois a consciência parece ser inerente ao que o sujeito tem a dizer como significação" (LACAN, 1999, p.111).

Consoante Milner (1987), os anagramas, cujo alcance nunca foi completamente avaliado, parecem começar por um problema de filologia: "um nome, unidade lexical ordinária, escolhido por um técnico para fim de codificação,

${ }^{7}$ No filme "Uma Mente Brilhante" - do diretor americano Ron Howard - , ganhador do Oscar 2002 de melhor filme, que narra a história do matemático John Nash - ganhador do Prêmio Nobel em 1994 - vemos como o matemático, que era esquizofrênico, abandona-se ao jogo combinatório dos números e letras. Saussure, por causa de seu trabalho, como afirma Milner (1987), passara a ser olhado com olhos atravessados. 
e subsistindo, distinto, como chave criptográfica" (MILNER, op. cit.:57 ). De um lado ou de outro, não se vê mais que o mesmo material que os causa, o significante. Se eles "têm o ar de nada terem a ver com o que os causa", é porque a gente espera que aquilo que os causa tenha certa relação com o real (LACAN, 1999, p.31)

Milner considera que os Anagramas se colocam num lugar diferente do CLG em que tudo parece estar regrado pelo diferencial. Naqueles, o diferencial parecia sucumbir mediante certa "positividade", subsistindo "(n)um lugar de direito localizável em todo verso", de sorte que a hipótese saussuriana negaria a própria idéia de signo conservada por ele. O anagrama estaria longe de ser diferencial, pois fala de um determinado nome tratado como dado em si, e não na rede de oposições, a partir da qual os fonemas são redistribuídos. Acrescenta-se a isto o fato de que o anagrama transgride o estatuto da descrição que faz de uma unidade linguística o suporte de uma presença e uma ausência. É que a isto o anagrama não se presta, uma vez que ele subsiste na forma explícita (MILNER, 1987, p.56).

Por essas questões, Milner entende que a procura de Saussure nos anagramas ou o movimento que o havia conduzido a querer sustentar o "um" no seio dos equívocos sonoros do verso latino é encontrado em outro lugar: no CLG. No fim das contas, olhando-os bem, o CLG "reconhecido pelos universitários" e "os folhetos de poética, ignorados por eles", não dizem nada mais que a mesma coisa: o "um" que marca as línguas vem de outro lugar: da diferença. (MILNER, op. cit., p.68).

\section{CONSIDERAÇÕES FINAIS}

Espera-se sempre de um texto uma conclusão, mas é necessário, nesse caso, continuar, pois, olhando bem, as relações paradigmáticas saussurianas produzem efeitos de toda ordem. Continuemos com um fato, no mínimo curioso. Ao defender que a língua não é uma forma "fixa", e que não devemos nos prender unicamente na camada horizontal da língua, sendo necessário ter "idéia do fenômeno sóciohistórico que atrai imediatamente o turbilhão de signos da coluna vertical" (SAUSSURE, apud BOUQUET, 1999, p. 175), Saussure visualiza o fenômeno "sócio-histórico" na coluna vertical, dando a entender que os sentidos já dados em algum lugar seriam projetados, virtualmente, na coluna horizontal. Essa coluna vertical estaria sendo entendida como o espaço de certa historicidade, por assim dizer, dos já-ditos, das cadeias estabilizadas. É Milner (2002) quem afirma exemplarmente que "somente há virtual enquanto imaginário".

Não poderia ainda deixar de lado o efeito que as relações paradigmáticas provocaram em outro espaço discursivo, qual seja, a psicanálise lacaniana. Ao reler o signo linguístico, Lacan desloca o significante, agora em maiúsculo, para cima do traço e o significado, em minúsculo e itálico, para baixo, lendo o traço como uma "barreira resistente à significação", mais precisamente, uma barra, que nasce de uma especial escuta anagramática da palavra francesa "arbre", com a qual se traduz "arbor" utilizada por Saussure no capítulo sobre a "Natureza do 
ALVES DE LIMA - No (per)curso de Ferdinand de Saussure...

signo linguístico". Com esse movimento, o psicanalista evidencia que conquanto a linearidade da cadeia sintagmática seja necessária, não é suficiente, pois

não há cadeia significante, com efeito, que não sustente, como que apenso na pontuação de cada uma de suas unidades, tudo o que se articula de contextos atestados na vertical, por assim, dizer, desse ponto (LACAN, 1998, p. 507).

Considerando os efeitos das releituras lacanianas, bem como seu construto, Teresa Lemos (1994) nos leva a Milner quando defende que o linguista, diretamente implicado com a formalização do funcionamento da língua, deve ter um compromisso ético, qual seja, "iluminar a relação da língua à alíngua" (MILNER, 1987, p.16). Tal compromisso coloca a Linguística num lugar em que é "afetada pela possibilidade da Psicanálise". Estar "afetada" pela possibilidade da Psicanálise não implicaria querer restituir, como aponta Teresa Lemos (1994), algo que falta à Linguística, mas acreditar que é possível estabelecer uma interlocução entre dois campos discursivos em que um se deixa afetar pelo discurso do outro, ou, mediante sua exposição ao saber do outro, como acentua Nina Leite $(1994)^{8}$.

\section{REFERÊNCIAS BIBLIOGRÁFICAS}

ARRIVÉ, Michel. (1999). Linguagem e psicanálise, linguística e inconsciente: Freud, Saussure, Pichon, Lacan. Rio de Janeiro: Jorge Zahar.

BOUQUET, Simon. (1999). Introdução à leitura de Saussure. São Paulo: Cultrix.

GADET, Françoise \& PÊCHEUX, Michel. (1981). La langue introuvable. Paris: François Maspero.

GODEL, Robert. (1969). Les sources manuscrites du cours de linguistique générale de F. de Saussure. Genève: Libraire Droz.

de LEMOS, Teresa Guimarães. (1994). A Lingua que me falta: uma análise dos estudos em aquisição da linguagem. Campinas:IEL/UNICAMP.

LEMOS, C. T. G. (1998). “A poética e o significante”. Eco 2, Maceió (AL).

LACAN, Jacques. (1999). O Seminário -Livro 5: As formações do inconsciente. Rio de Janeiro: Jorge Zahar.

\footnotetext{
${ }^{8}$ Arrivé destaca que, na história da Linguística e da Psicanálise, as relações entre estes domínios estiveram muito mais próximas do que se supõe. Alguns indícios podem ser vistos: a leitura dos trabalhos desenvolvidos pelo filho de Saussure, Raymond de Saussure, por Sigmund Freud - o próprio Raymond sugeriu, em carta a Charles Bally, um encontro entre a Linguística saussuriana e a Psicanálise -; as reflexões freudianas sobre as pesquisas do filólogo Karl Abel, que muito lhe ajudaram para compreender o funcionamento do sonho; a presença do material linguístico na obra de Sigmund Freud, "Os chistes e sua relação com o Inconsciente"; os trabalhos sobre os Anagramas desenvolvidos por Saussure falando de um arranjo diferente da ordem no tempo em que se apresentam os elementos. Como assenta Michel Arrivé (op.cit.:21), "cada um, à sua maneira, Freud e Saussure assinalam a possibilidade e a necessidade de um contato e de uma colaboração entre linguística e psicanálise".
} 
LACAN, Jacques. (1998). Escritos. Rio de Janeiro: Jorge Zahar Ed. . (1985). O Seminário-Livro 3. Rio de Janeiro: Jorge Zahar. (1970). "Radiophonie - Seminário de 05/06/1970".In. <http:/www. ecole-lacanienne.net>.

LEITE, Nina V. de A. (1994). Psicanálise e Análise do Discurso: o acontecimento na estrutura. Rio de Janeiro: Campo Matemático.

MILNER, Jean-Claude. (2002). Le périple structural. La couleur des idées, Paris: Seuil. (1989). Introduction à une science du langage. Paris: Seuil. . (1987). O Amor da Língua. Porto Alegre: Artes Médicas. (1983). Les noms indistints. Paris: Seuil.

NORMAND, Claudine. (1990). La quadratura du sens. Paris: Preisses Universitaires de France. . (2000). Saussure. Paris: Les Belles Lettres.

SAUSSURE, Ferdinand de. (1999). Curso de Linguística Geral. São Paulo: Cultrix. . (1982). Cours de Linguistique Gènèrale . Édition critique préparée par Tulio de Mauro. Paris: Payot. . (2002). Écrits de linguistique générale. Texte établi et édité par Simon Bouquet et Rudolf Engler. Paris: Éditions Gallimard.

STAROBINSKI, Jean. (1974). As palavras sob as palavras - os anagramas de Ferdinand de Saussure. São Paulo: Editora Perspectiva S\&A. 
